that of quality. When Mr. Ray has read again my detailed statement of method he will be the first to thank me for having introduced some principle of comparison where none has hitherto existed. I am convinced that this coefficient of quality amounts to more than a makeshift; its value will exist in its applicability as a constant factor. Mr. Ray cites my determination of coefficient 93 for Nguna and 76 for Sesake, "the same language, Sesake being a colony from Nguna." The lower coefficient of Sesake is not a matter of mere opinion; it is the mathematical product of the presence in that language of several consonant mutations expressive of a wider divarication from the Proto-Samoan stem. If we were in possession of practically complete dictionaries of Nguna and Sesake, this coefficient of quality would, in my best judgment, still be applicable. Suppose that such dictionaries should exhibit Nguna as having Proto-Samoan loan material quantitatively to the extent of 100 words to the thousand, and Sesake 125; of course, it is understood that I am using figures symbolically. We should err in assigning to Nguna a to per cent. Proto-Samoan element and to Sesake $12 \frac{1}{2}$ per cent. We should have to regard quality as well as quantity; we should have to employ my quality coefficient (subject to such recomputation as a better supply of data would make possible) as an essential factor. Thus Nguna, as a result of the combination of the two elements, would be indicated by 9.3 per cent. and Sesake by 9.5 per cent. Then and thus only will it be possible to state positively that Nguna and Sesake have received the same influence from the Proto-Samoan, the question of whether qua Melanesian they are the same language being a matter wholly distinct.

It was of set purpose that I have omitted the discussion of the syntax of the grammar of Oceanic languages. Our present material is all stated most inaccurately; our authorities, without exception, have stated their considerations of grammar in terms of the grammatical categories of inflected speech. The grammar of these isolating languages must be newly written. It will form a large part of the Samoan dictionary of Polynesian philology upon which I am now engaged. In various publications I have made preliminary announcement of some of the principles of this grammar-e.g. in my monograph on the Beach-la-mar jargon, just published, I have dealt with the evolution of the verb in the diffuse attributive; but in the present incomplete stage of the study it did not seem advisable in the volume under review to seek to exceed the phonetic examination of the material there assembled.

New York, August 28 . William Churchill.

IN my review of Mr. Churchill's book, "The Polynesian Wanderings," I certainly intended my remark as to the liability of error arising from deficient and imperfect material to apply both to quantitative and qualitative comparisons. With regard to the former, there can be no dispute, and the impracticability of quantitative comparison was recognised by Mr. Churchill on p. I43 of his book. But a qualitative comparison as given by $\mathrm{Mr}$. Churchill in his tables, and referred to in the letter, seems to be equally liable to error through inaccuracy in the material. Referring again to the tables for Nguna and Sesake, which I took as typical cases, Mr. Churchill finds that the lower coefficient of Sesake-i.e, 76 as opposed to Nguna 93 (implying that Sesake was less like Polynesian than Nguna)-was due to the presence in Sesake " of several consonant mutations expressive of a wider divarication from the Proto-Samoan stem." Mr. Churchill's Sesake words were taken from the lists of Codrington and Gabelentz. The source of his much shorter list in Nguna is not stated. Using a longer list by Bp. Patteson (from which those of Codrington and Gabelentz were derived) and a very long (MS.) vocabulary of Nguna, I find that all $\mathrm{Mr}$. Churchill's examples in Sesake are identical with Nguna, and all the Nguna are identical with Sesake. The consonant mutations are the same. Thus the quality of the likeness to Polynesian is the same for both languages, and the great difference in Mr. Churchill's results is entirely due to the lists being defective and appearing under different names. For the accurate No. 2 I 86 , vOL. 87$]$ application of Mr. Churchill's comparisons the vocabularies used must be equal in extent and signification.

My desire in the note on Mr. Churchill's omission to discuss grammar was to direct attention to the fact that he had not shown that any distinctively Polynesian particles (as, e.g., the article te, the verbal signs kua, na, the so-called possessive words loku, toku, \&c.) were used in Melanesian languages.

\section{Habits of Dogs.}

I HAVE read with interest the letter of Miss Everett in your issue of August 31 on dogs eating wasps, as I have a poodle which also eats them, with evident satisfaction. He generally catches them alive, but will also pick them up from the floor when recently killed; he evidently suffers somewhat from the sting, but only for ten or fifteen seconds.

I have always attributed this liking for wasps to some stimulating action of the poison similar to that produced by formic acid on man; this idea was suggested by the following plan, learned in Switzerland.

If a freshly peeled wand be plunged into an ants' nest, so as to be bitten by the infuriated ants, and is then passed between the lips, a sensation of refreshment is experienced which appears to be out of proportion to the effect which one would expect from the mere acidity.

I believe that I have read somewhere that formic acid is a stimulant. ROBERT Venables.

8 rue du Sundgau, Mulhouse, Alsace, September 8.

ON p. 348 Dr. Kidd asks if it is known to be a common thing for dogs to carry hedgehogs in their mouths. I can only answer for my own dog, a fox-terrier. Last season a hedgehog strayed into our garden, and appeared anxious to stay; but the dog carried it in his mouth repeatedly, and so teased it in various ways, that we were not surprised when the hedgehog beat a permanent retreat by absconding. The curious circumstance in the affair was that the dog appeared to carry the hedgehog, rolled in a ball, without causing his lips to bleed; in this particular, Carlo seems to be cleverer than Dr. Kidd's dog!

Braewyn, Earlsfield Road, Wandsworth Common.

\section{R. Hooper Pearson.}

\section{A Gilbert White Manuscript.}

Mention has been made in the Press of the recent sale of a hitherto unpublished manuscript by Gilbert White. It consists of a nature calendar which the author of "The Natural History of Selborne" carefully drew up before he wrote the first of the letters which are the basis of his famous book. To the latter, he tells us, he meant to add an "Annus Historico-Naturalis," and it seems that the MS. in question was intended to be used in this connection. I anr $_{1}$ pleased to say that the Selborne Society will shortly produce the calendar (which is particularly interesting) in facsimile, and print a limited edition on Italian hand-made paper.

I should be glad to give further particulars to any of the many admirers of Gilbert White who would care to have them.

Wilfred Mark WebB.

The Selborne Society, 42 Bloomsbury Square, London, W.C., September 19.

\section{Miniature Rainbows.}

THE recent letters on miniature rainbows recalled to my mind a rather interesting case which I observed some years ago at Inversnaid, on Loch Lomond. Here a small stream makes a pretty waterfall; and while standing beside the pool at the base of the fall, and directly opposite the fall itself, I noticed first a brilliant rainbow reflected in the pool. The actual bow was formed in the spray above the pool, and, unless my recollection is greatly at fault, it appeared less brilliant than its reflection. But the bow and its reflected image, viewed together across the pool, formed an almost complete circle, broken only where the extremities of the real bow in the spray appeared to come down towards the surface of the pool.

\section{Giltar, Shrewsbury Lane, Shooters Hill,} A. L. Leach. September 16. 